\title{
Pertumbuhan Tanaman Pamelo (Citrus maxima (Burm.) Merr.) pada Berbagai Komposisi dan Volume Media Tanam
}

\author{
The Growth of Pummelo (Citrus maxima (Burm.) Merr.) at Various Plant Media \\ Composition and Volume
}

Arifah Rahayu $^{1 *}$, Setyono ${ }^{1}$, dan Slamet Susanto ${ }^{2}$

Diterima 11 Februari 2016/Disetujui 16 Maret 2016

\begin{abstract}
This study was aimed at determining the planting media composition and media volume for pummelo growth. A complete randomized design with two factors was arranged in this experiment. The first factor was planting media composition, consisting of (1) rice hull charcoal : soil $=1: 1$, (2) cocopeat : soil $=1: 1$, (3) cocopeat : rice hull charcoal $=1: 1$, (4) rice hull charcoal $:$ cocopeat : soil $=1: 1: 1$, and (5) soil as control. The second factor was media volume, namely 10, 20, and 30 $L$. The results showed that plant height, leaf number, root volume and $P$ leaf concentration of pummelo grown in $30 \mathrm{~L}$ media were significantly higher than those of pummelo grown in $10 \mathrm{~L}$ media, but were not different from those of grown in $20 \mathrm{~L}$ media, except for leaf number. Plant height, root volume and $N$ leaf content of pummelo grown in rice hull charcoal : soil relatively were higher than those grown in rice hull charcoal : cocopeat. Planting media composition of rice hull charcoal : cocopeat had $\mathrm{N}$ and $\mathrm{C}$ content, $\mathrm{C} / \mathrm{N}$ ratio, organic matter, $\mathrm{K}_{2} \mathrm{O}$ and cation exchange capacity higher, but had water content, bulk density, particle density lower than other growing medium. The most suitable planting medium for potted pummelo was rice hull charcoal : soil, and 20 L medium volume was still suitable until 24 WAP (weeks after planting).
\end{abstract}

Key words: cocopeat, $N$ and $P$ leaves content, rice hull charcoal, root volume,

\begin{abstract}
ABSTRAK
Penelitian ini bertujuan untuk mengetahui komposisi dan volume media tanam yang sesuai untuk pertumbuhan tanaman pamelo. Penelitian ini menggunakan rancangan acak lengkap (RAL) faktorial dengan dua faktor yaitu komposisi media tanam dan volume media tanam. Komposisi media tanam terdiri atas lima taraf, yaitu (1) arang sekam : tanah (1:1), (2) cocopeat : tanah (1:1), (3) cocopeat : arang sekam (1:1), (4) arang sekam : cocopeat : tanah (1:1:1), dan (5) tanah (kontrol), sedangkan volume media tanam terdiri atas tiga taraf (10, 20, dan $30 \mathrm{~L})$. Hasil penelitian menunjukkan bahwa tinggi, jumlah daun, volume akar dan kandungan $\mathrm{P}$ daun tanaman pamelo pada volume media tanam $30 \mathrm{~L}$ lebih besar dibandingkan dengan pada media $10 \mathrm{~L}$, tetapi tidak berbeda nyata dengan pada media tanam $20 \mathrm{~L}$, kecuali jumlah daun. Tinggi tanaman, volume akar dan kandungan $\mathrm{N}$ daun tanaman pamelo pada media arang sekam : tanah relatif lebih besar dibandingkan dengan pada media arang sekam : cocopeat. Media tanam arang sekam : cocopeat memiliki kandungan $\mathrm{N}, \mathrm{C}$, nisbah $\mathrm{C} / \mathrm{N}$, bahan organik, $\mathrm{K}_{2} \mathrm{O}$ dan nilai tukar kation lebih tinggi, tetapi kadar air, bobot isi dan bobot jenis lebih rendah dibandingkan dengan media tanam lain. Dengan demikian, komposisi media tanam yang paling sesuai untuk tanaman pamelo adalah arang sekam : tanah dan volume media tanam $20 \mathrm{~L}$ masih sesuai untuk tanaman pamelo hingga 24 MST (minggu setelah tanam).
\end{abstract}

Kata kunci: arang sekam, cocopeat, kandungan $\mathrm{N}$ dan $\mathrm{P}$ daun, volume akar

\footnotetext{
${ }^{1}$ Program Studi Agroteknologi Universitas Djuanda, Jl. Tol Ciawi 1, Kotak Pos Ciawi 35 Bogor 16720 Telp/Fax. 02518241732.

${ }^{2}$ Departemen Agronomi dan Hortikultura IPB, Jl Meranti Kampus IPB Darmaga Bogor 16680

Email korespondensi: arifah.rahayu@unida.ac.id
} 


\section{PENDAHULUAN}

Budidaya tanaman buah dalam pot (tabulampot) merupakan alternatif untuk mengusahakan tanaman buah di lahan sempit, untuk mengatasi keterbatasan lahan di daerah perkotaan. Pengusahaan tabulampot dapat diintegrasikan dengan program pemanfaatan pekarangan, sehingga tidak hanya ditujukan untuk menghasilkan buah, tetapi juga untuk dinikmati keindahan penampilan tanamannya, sebagai bagian dari taman rumah dan/atau lingkungan. Keuntungan teknik budidaya ini antara lain dapat mengatasi masalah yang berkaitan dengan tanah (penyakit tular tanah, sifat fisik dan kesuburan tanah) dan mempermudah kegiatan pemeliharaan tanaman (pemupukan, pengendalian organisme pengganggu tanaman, penyiraman dan pengendalian pertumbuhan).

Umumnya hampir semua jenis jeruk dapat ditanam di dalam pot, termasuk jeruk besar atau pamelo (Citrus maxima (Burm.) Merr.). Kandungan antioksidan buah pamelo cukup tinggi, baik berupa vitamin $\mathrm{C}$ dan vitamin $\mathrm{E}$, maupun karotenoid dan fenolik (limonoid dan flavonoid) (Tsai et al., 2007).

Di antara kendala yang dihadapi pada penanaman dalam pot adalah porositas dan kemampuan menahan air dan hara media tumbuh, sehingga diperlukan pengaturan komposisi media tanam yang tepat. Selama ini, media tanam yang banyak digunakan adalah tanah lapisan atas (topsoil), namun topsoil yang baik untuk media tanam tidak selalu segera tersedia di daerah perkotaan. Selain itu, penggunaan tanah untuk tabulampot tanpa campuran dapat menyebabkan media tanam mudah mengalami pemadatan, sehingga porositas dan kemampuan menahan airnya menurun. Oleh karena itu, perlu digunakan bahan organik yang merupakan limbah pertanian, seperti arang sekam padi dan serbuk sabut kelapa (cocopeat). Kedua bahan organik ini memiliki porositas dan daya pegang air yang baik, serta mengandung hara makro (Nurhidayati dan Maryati, 2014; Shanmugasundaram et al., 2014).

Penggunaan media arang sekam : tanah pada tanaman seledri menghasilkan jumlah daun, luas daun, jumlah tangkai daun, tinggi tanaman, bobot basah dan kering brangkasan dan hasil lebih tinggi dibandingkan dengan pada media serbuk gergaji : tanah (Kusmarwiyah dan Erni, 2011). Menurut Ikeura et al. (2012), produksi optimum zucchini dalam pot bervolume $15 \mathrm{~L}$ dicapai pada komposisi media tanam arang sekam dan peat moss 80:20. Sementara itu komposisi media terbaik pada bibit 'Rough Lemon' adalah pasir dan gambut 1:1 (Khan, 2006) dan pada bibit durian adalah tanah, kompos, pukan ayam, dan sekam (Muryati et al., 2009).

Penanaman dalam pot menyebabkan pertumbuhan akar terbatas, yang berakibat menurunkan pertumbuhan tajuk. Tanaman mandarin 'Ponkan' yang akarnya dibatasi dengan kantong bervolume $20 \mathrm{~L}$ mengalami penurunan tinggi (14-29\%), volume tajuk (43$66 \%)$, lingkar batang (10-22\%) dan luas daun (8-22\%), tetapi padatan terlarut total (PTT) dan indeks warna buah meningkat (Mataa dan Tominaga, 1998). Pengurangan ukuran pot pada tanaman jagung dan kedelai juga menyebabkan penurunan bobot kering tajuk dan jumlah air yang ditranspirasikan (Ray dan Sinclair, 1998), walaupun demikian tinggi tanaman bunga matahari yang ditanam pada pot berukuran $650 \mathrm{~mL}$ dan $1.2 \mathrm{~L}$ tidak berbeda nyata (Whipker dan Dasoju, 1998).

Informasi mengenai komposisi dan volume media tanam yang optimum untuk pertumbuhan bibit pamelo dalam pot masih terbatas. Penelitian ini bertujuan untuk mendapatkan komposisi dan volume media tanam yang sesuai untuk pertumbuhan tanaman pamelo.

\section{BAHAN DAN METODE}

Penelitian dilakukan mulai bulan Mei sampai dengan Nopember 2014. Penanaman bibit tanaman pamelo dilakukan di Kebun Percobaan Jurusan Agroteknologi, Universitas Djuanda, Bogor. Sifat kimia dan fisik media tanam dan kandungan hara daun dianalisis di Laboratorium Balai Penelitian Tanah, Balai Besar Sumberdaya Lahan Pertanian, Bogor.

Bahan yang digunakan adalah bibit pamelo 'Bageng Taji' asal cangkok berumur satu tahun yang diperoleh dari Desa Bageng, Kecamatan Gembong, Kabupaten Pati. Bahan lain yang digunakan adalah polibag, pot plastik bervolume 10, 20 dan $30 \mathrm{~L}$, media tanam (arang sekam (A), cocopeat (C) dan tanah (T), pupuk NPK, fungisida, pestisida dan bahan kimia untuk analisis hara. Alat yang 
diperlukan meliputi paranet $40 \%$, alat pengolah tanah, gunting setek, penyemprot punggung, $\mathrm{pH}$ meter, EC meter dan alat-alat laboratorium.

Rancangan percobaan yang digunakan adalah rancangan acak lengkap faktorial, yang terdiri atas dua faktor, yaitu komposisi media tanam dan volume media tanam. Komposisi media tanam diukur berdasarkan volume, terdiri atas lima taraf, yaitu (1) arang sekam : tanah $=1: 1$, (2) cocopeat $:$ tanah $=1: 1$, , (3) arang sekam : cocopeat $=1: 1$, (4) arang sekam $:$ cocopeat $:$ tanah $=1: 1: 1$, dan (5) tanah. Volume media tanam terdiri atas tiga taraf, yaitu 10, 20, dan 30 L. Setiap perlakuan diulang tiga kali, sehingga terdapat 45 satuan percobaan. Setiap satuan percobaan terdiri atas dua pot, sehingga seluruhnya terdapat 90 pot.

Pupuk yang digunakan adalah NPK (1515-15) dan ZA masing-masing dengan konsentrasi $15 \mathrm{~g} \mathrm{~L}^{-1}$, dan dosis $100 \mathrm{~mL}$ per pot. Selain itu tanaman pamelo diberi pupuk daun $\left(2 \mathrm{~g} \mathrm{~L}^{-1}\right)$, dengan cara disemprotkan ke permukan daun secara merata. Pemupukan dilakukan setiap dua minggu sekali. Pengendalian hama, penyakit dan gulma disesuaikan dengan standar yang berlaku.

Pengamatan dilakukan terhadap peubah tinggi tanaman, jumlah daun, luas daun, panjang tunas, jumlah tunas dan volume akar pada 24 MST. Kandungan N dan $\mathrm{P}$ daun dianalisis pada 16 MST dengan metode Kjeldahl untuk analisis $\mathrm{N}$ dan pengabuan kering untuk P. Selain itu, dilakukan analisis sifat kimia $\left(\mathrm{pH}\right.$, kandungan $\mathrm{N}, \mathrm{P}_{2} \mathrm{O}_{5}, \mathrm{~K}_{2} \mathrm{O}$, KTK dan basa-basa dapat ditukar) dan sifat fisik (kadar air, bobot isi dan bobot jenis) media tanam pada pot bervolume $20 \mathrm{~L}$. Kandungan hara pada media tanam, diukur pada umur 16 MST (minggu setelah tanam). Kandungan $\mathrm{N}$ dianalisis dengan metode Kjeldahl, P dengan metode Olsen dan Bray I dan K dengan metode Morgan. Sifat kimia dan fisik media tanam, masing-masing diukur pada umur 16 dan 24 MST. Data dianalisis dengan sidik ragam. Bila terdapat pengaruh perlakuan dilanjutkan dengan Uji Jarak Berganda Duncan pada taraf 0.05.

\section{HASIL DAN PEMBAHASAN}

\section{Pertumbuhan Tanaman}

Peningkatan volume media tanam nyata meningkatkan tinggi tanaman, jumlah daun dan volume perakaran (Tabel 1). Hal ini tampak pada tanaman dengan volume media tanam $30 \mathrm{~L}$ yang nyata lebih tinggi dibandingkan yang ditanam pada media $10 \mathrm{~L}$, tetapi tidak berbeda nyata dengan pada media 20 L. Jumlah daun pada volume media tanam $30 \mathrm{~L}$ nyata lebih banyak dibandingkan dengan pada media 10 dan 20 L. Volume akar tanaman pamelo pada media $20 \mathrm{~L}$ dan $30 \mathrm{~L}$ nyata lebih besar dibandingkan dengan pada media 10 L. Meskipun demikian, luas daun, jumlah dan panjang tunas tanaman pamelo tidak dipengaruhi oleh volume media. Hal senada disampaikan oleh Yang et al. (2010), bahwa tanaman jagung dan sorgum yang ditanam pada pot kecil menghasilkan bobot pucuk total lebih rendah, sehingga memiliki nisbah akar/pucuk lebih besar dibandingkan dengan pot besar. Demikian pula, Surata (2012) melaporkan, bahwa penambahan ukuran plastik media semai meningkatkan pertumbuhan tinggi, diameter, persen hidup, bobot kering total, kualitas bibit dan menurunkan nisbah pucuk akar cendana pada umur 6 bulan. Van Iersel (1997) menyatakan bahwa penurunan pertumbuhan pada tanaman salvia (Salvia splendens) yang ditanam pada pot berukuran kecil disebabkan oleh laju asimilasi bersih yang rendah, sedangkan pertumbuhan yang pesat pada tanaman di pot besar disebabkan oleh nisbah luas daun yang lebih besar.

Komposisi media tanam hanya berpengaruh nyata terhadap peubah tinggi tanaman dan volume akar. Tinggi tanaman dan volume akar pamelo pada media arang sekam : cocopeat relatif lebih rendah dibandingkan dengan pada media lain. Sementara itu, tinggi tanaman pamelo pada media arang sekam : tanah paling tinggi dibandingkan dengan media lain, tetapi volume akar pada media ini tidak berbeda nyata dengan media lain (Tabel 1). Komposisi media tanam arang sekam : tanah lebih sesuai untuk tanaman pamelo, karena dapat saling melengkapi. Hasil analisis menunjukkan, tanah yang digunakan dalam penelitian ini mengandung $4 \%$ pasir, $32 \%$ debu dan $64 \%$ liat, sehingga mudah memadat. Penambahan arang sekam dapat memperbaiki porositas media, sehingga proses respirasi akar berlangsung baik. Selain itu, kemampuan arang sekam mengikat air dan melepaskannya pada pori mikro, akan mendorong pertumbuhan mikroorganisme yang bermanfaat 
(Kusmarwiyah dan Erni, 2011). Theeba et al. (2012) menambahkan, bahwa arang sekam dapat memperbaiki sifat kimia dan fisik tanah, karena memiliki pH (8.9), KTK (17 $\left.\mathrm{cmol} \mathrm{kg}^{-1}\right)$ yang tinggi dan luas permukaan $\left(401 \mathrm{~m}^{2} \mathrm{~g}^{-1}\right)$ yang besar.

\section{Kandungan Nitrogen dan Fosfor Daun}

Volume media tanam berpengaruh nyata terhadap kandungan $\mathrm{P}$, tetapi tidak berpengaruh nyata terhadap kandungan $\mathrm{N}$ daun pada 16 MST. Kandungan fosfor daun tanaman pamelo pada media bervolume 30 dan 20 L nyata lebih besar dibandingkan dengan bervolume $10 \mathrm{~L}$ (Tabel 2). Diduga hal tersebut berhubungan dengan volume perakaran yang lebih besar pada pot berukuran besar (Tabel 1), sehingga memiliki kemampuan menyerap fosfat lebih baik. Walaupun tidak dipengaruhi secara nyata, kandungan $\mathrm{N}$ cenderung lebih tinggi dengan semakin besarnya volume media.

Komposisi media tanam berpengaruh nyata terhadap kandungan $\mathrm{N}$ dan $\mathrm{P}$ daun. Kandungan nitrogen daun tanaman pamelo pada media tanam arang sekam : tanah nyata lebih besar dibandingkan dengan pada media arang sekam : cocopeat dan tanah saja, tetapi tidak berbeda nyata dengan komposisi media lainnya (Tabel 2). Hal ini berkaitan kemampuan arang sekam menjerap hara, termasuk $\mathrm{N}$ pada pupuk (Theeba et al., 2012). Nitrogen berperan mendorong pertumbuhan vegetatif, sehingga kandungan nitrogen daun yang besar membuat tanaman tumbuh lebih cepat, yang tampak dari tinggi tanaman pada media arang sekam : tanah yang lebih besar (Tabel 1).

Tabel 1. Tinggi tanaman, jumlah daun, jumlah tunas dan panjang tunas tanaman pamelo pada umur 24 minggu setelah tanam

\begin{tabular}{lcccccc}
\hline Perlakuan & $\begin{array}{c}\text { Tinggi } \\
\text { Tanaman } \\
(\mathrm{cm})\end{array}$ & $\begin{array}{c}\text { Jumlah } \\
\text { Daun } \\
(\text { helai })\end{array}$ & $\begin{array}{c}\text { Luas Daun } \\
\text { Total } \\
\left(\mathrm{cm}^{2}\right)\end{array}$ & $\begin{array}{c}\text { Jumlah } \\
\text { Tunas } \\
\text { Total }\end{array}$ & $\begin{array}{c}\text { Panjang } \\
\text { Tunas Total } \\
(\mathrm{cm})\end{array}$ & $\begin{array}{c}\text { Volume } \\
\text { Akar } \\
\left(\mathrm{dm}^{3}\right)\end{array}$ \\
\hline Volume Pot & & & & & & \\
10 L & $145.03^{\mathrm{a}}$ & $126.0^{\mathrm{a}}$ & 177.02 & 15.2 & 38.29 & $50.40^{\mathrm{a}}$ \\
20 L & $154.07^{\mathrm{ab}}$ & $140.8^{\mathrm{a}}$ & 168.41 & 15.8 & 41.81 & $71.33^{\mathrm{b}}$ \\
30 L & $164.93^{\mathrm{b}}$ & $161.0^{\mathrm{b}}$ & 174.48 & 13.9 & 35.93 & $83.30^{\mathrm{b}}$ \\
Komposisi Media & & & & & & \\
A:T (1:1) & $166.06^{\mathrm{b}}$ & 135.9 & 176.78 & 16.2 & 38.37 & $65.68^{\mathrm{ab}}$ \\
C:T $(1: 1)$ & $143.44^{\mathrm{a}}$ & 137.1 & 161.16 & 13.2 & 38.90 & $81.67^{\mathrm{b}}$ \\
A:C $(1: 1)$ & $144.44^{\mathrm{a}}$ & 144.7 & 173.67 & 13.2 & 35.88 & $58.08^{\mathrm{a}}$ \\
A:C:T $(1: 1: 1)$ & $157.11^{\mathrm{ab}}$ & 157.6 & 176.48 & 17.2 & 47.91 & $74.66^{\mathrm{ab}}$ \\
T & $162.33^{\mathrm{b}}$ & 137.7 & 178.41 & 12.0 & 32.17 & $61.65^{\mathrm{ab}}$ \\
\hline Ken
\end{tabular}

Keterangan: Nilai rata-rata pada kolom yang sama diikuti huruf yang sama tidak berbeda nyata menurut uji selang berganda Duncan taraf 5\%. A: arang sekam, T: tanah, C: cocopeat

Tabel 2. Kandungan N dan P daun tanaman pamelo pada 16 MST

\begin{tabular}{lll}
\hline Perlakuan & $\mathrm{N}(\%)$ & $\mathrm{P}(\%)$ \\
\hline Volume Pot & & \\
$10 \mathrm{~L}$ & 2.74 & $0.13^{\mathrm{a}}$ \\
20 L & 2.77 & $0.14^{\mathrm{b}}$ \\
$30 \mathrm{~L}$ & 2.79 & $0.14^{\mathrm{b}}$ \\
Komposisi Media & & \\
A:T (1:1) & $2.96^{\mathrm{c}}$ & $0.12^{\mathrm{a}}$ \\
C:T (1:1) & $2.72^{\mathrm{abc}}$ & $0.14^{\mathrm{b}}$ \\
A:C $(1: 1)$ & $2.64^{\mathrm{ab}}$ & $0.17^{\mathrm{c}}$ \\
A:C:T $(1: 1: 1)$ & $2.94^{\mathrm{bc}}$ & $0.12^{\mathrm{a}}$ \\
T & $2.58^{\mathrm{a}}$ & $0.11^{\mathrm{a}}$ \\
\hline
\end{tabular}

Keterangan: Nilai rata-rata pada kolom yang sama diikuti huruf yang sama tidak berbeda nyata menurut uji selang berganda Duncan taraf 5\%. A: arang sekam, T: tanah, C: cocopeat 
Tanaman pada media arang sekam : cocopeat memiliki kandungan fosfor daun nyata lebih besar dibandingkan media lain (Tabel 2). Kondisi ini berkaitan dengan hasil analisis media tanam yang menunjukkan kandungan $\mathrm{P}_{2} \mathrm{O}_{5}$ (Olsen) pada komposisi media ini jauh lebih tinggi dibandingkan dengan media lainnya (Tabel 4). Hal demikian disebabkan arang sekam mengandung fosfor yang cukup tinggi. Arang sekam mengandung $0.14 \% \mathrm{~N}, 0.15 \% \mathrm{P}_{2} \mathrm{O}_{5}, 0.31 \% \mathrm{~K}_{2} \mathrm{O}, 0.28 \% \mathrm{Ca}$, $0.32 \% \mathrm{Mg}$ dan $1.35 \% \mathrm{Na}$ (Nurhidayati dan Maryati, 2014), sedangkan cocopeat mengandung $0.14 \% \mathrm{~N}, 0.04 \% \mathrm{P}, 0.65 \% \mathrm{~K}^{+}$, $9.75 \% \mathrm{Ca}^{2+}$ dan $0.25 \% \quad \mathrm{Mg}$ (Shanmugasundaram et al., 2014). Arang sekam padi juga mampu melepaskan fosfor lebih tinggi dibandingkan dengan arang kayu dan arang tempurung kelapa (Soemeinaboedhy dan Tejowulan, 2007). Walaupun demikian, serapan $\mathrm{P}$ yang tinggi tidak diikuti oleh peningkatan tinggi tanaman dan volume akar pada 24 MST (Tabel 1). Hal ini hampir sama dengan hasil penelitian Thamrin et al. (2013), bahwa hubungan antara konsentrasi fosfor daun pamelo dengan hasil buah memiliki korelasi sangat rendah, walaupun peningkatan kandungan fosfor daun sampai kisaran tertentu akan meningkatkan hasil relatif. Selain itu perbedaan posisi daun yang dijadikan contoh analisis juga berpengaruh. Lebih lanjut Thamrin et al. (2013) menyatakan, daun ketiga-empat setelah panen sebelumnya lebih berkorelasi dengan hasil buah pamelo, sementara pada penelitian ini menggunakan daun kelima-tujuh pada tanaman belum berproduksi (berumur 1 tahun).

\section{Sifat Kimia dan Fisik Media Tanam}

Komposisi media tanam berpengaruh nyata terhadap kandungan $\mathrm{C}, \mathrm{N}$, nisbah $\mathrm{C} / \mathrm{N}$ dan $\mathrm{K}_{2} \mathrm{O}$ pada media tanam, tetapi tidak berpengaruh terhadap $\mathrm{pH}$. Hasil uji lanjut menunjukkan kandungan $\mathrm{C}, \mathrm{N}$, nisbah $\mathrm{C} / \mathrm{N}$ dan $\mathrm{K}_{2} \mathrm{O}$ pada media tanam arang sekam : cocopeat nyata lebih tinggi dibandingkan dengan media tanam lainnya, termasuk dengan tanah sebagai kontrol (Tabel 3). Hal ini sejalan dengan hasil penelitian Zulkarnain et al. (2013), bahwa aplikasi bahan organik dapat meningkatkan $\mathrm{C}$ organik dan $\mathrm{N}$ total.

Nisbah C/N yang tinggi (>20) pada media arang sekam : cocopeat dapat membuat tanaman mengalami defisiensi $\mathrm{N}$, bila tidak diimbangi dengan penambahan pupuk N. Hal ini tampak dari kandungan $\mathrm{N}$ daun pada media arang sekam : cocopeat yang lebih rendah dibandingkan dengan pada media arang sekam : tanah (Tabel 2). Media arang sekam : tanah, memiliki nisbah $\mathrm{C} / \mathrm{N}$ paling rendah $(<10)$, tetapi kandungan $\mathrm{N}$ daun paling tinggi, karena bahan organik dengan nisbah $\mathrm{C} / \mathrm{N}$ rendah $(<10)$ akan menghasilkan laju mineralisasi lebih tinggi dibandingkan dengan yang memiliki C/N tinggi (>20) (Abera et al., 2012). Laju mineralisasi yang tinggi ditunjukkan oleh nilai potensial mineralisasi dan laju mineralisasi yang tinggi, sehingga pemberian bahan organik ke dalam tanah akan membuat aktivitas mikroorganisme perombak $\mathrm{N}$ dan C meningkat (Wijanarko et al., 2012).

Tabel 3. Nilai pH, N-total, C-organik dan kandungan $\mathrm{P}_{2} \mathrm{O}_{5}$ dan $\mathrm{K}_{2} \mathrm{O}$ pada 16 MST

\begin{tabular}{|c|c|c|c|c|c|c|c|}
\hline Komposisi Media & $\mathrm{pH} \mathrm{H}_{2} \mathrm{O}$ & $\mathrm{N}(\%)$ & $\mathrm{C}(\%)$ & $\mathrm{C} / \mathrm{N}$ & $\begin{array}{c}\mathrm{P}_{2} \mathrm{O}_{5} \text { Olsen } \\
(\mathrm{ppm})\end{array}$ & $\begin{array}{c}\mathrm{P}_{2} \mathrm{O}_{5} \\
\text { Bray } 1(\mathrm{ppm})\end{array}$ & $\begin{array}{c}\mathrm{K}_{2} \mathrm{O} \\
(\mathrm{ppm})\end{array}$ \\
\hline $\mathrm{A}: \mathrm{T}(1: 1)$ & 5.60 & $1.61^{\mathrm{a}}$ & $0.17^{\mathrm{ab}}$ & $9.50^{\mathrm{a}}$ & 253.50 & 163.85 & $780.50^{\mathrm{a}}$ \\
\hline C:T (1:1) & 5.70 & $6.79^{\mathrm{b}}$ & $0.23^{\mathrm{ab}}$ & $30.50^{c}$ & 310.00 & 98.25 & $1176.50^{\mathrm{a}}$ \\
\hline $\mathrm{A}: \mathrm{C}(1: 1)$ & 5.90 & $19.88^{\mathrm{c}}$ & $0.74^{\mathrm{c}}$ & $27.00^{\mathrm{bc}}$ & 1221.00 & 0.00 & $1970.50^{b}$ \\
\hline A:C:T (1:1:1) & 5.40 & $5.39^{\mathrm{b}}$ & $0.32^{\mathrm{b}}$ & $17.00^{\mathrm{ab}}$ & 230.50 & 144.65 & $809.50^{\mathrm{a}}$ \\
\hline $\mathrm{T}$ & 5.15 & $1.68^{\mathrm{a}}$ & $0.14^{\mathrm{a}}$ & $12.00^{\mathrm{a}}$ & 150.50 & 75.85 & $594.00^{\mathrm{a}}$ \\
\hline
\end{tabular}

Keterangan: Nilai rata-rata pada kolom yang sama diikuti huruf yang sama tidak berbeda nyata menurut uji selang berganda Duncan taraf 5\%. A: arang sekam, T: tanah, C: cocopeat 
Komposisi media tanam berpengaruh terhadap kapasitas tukar kation (KTK). kandungan $\mathrm{Ca}, \mathrm{Mg}, \mathrm{K}, \mathrm{Na}$ dan jumlah kation. Kapasitas tukar kation, kandungan $\mathrm{Ca}, \mathrm{Mg}, \mathrm{K}$, $\mathrm{Na}$ dan jumlah kation pada media tanam arang sekam : cocopeat nyata lebih tinggi dibandingkan dengan komposisi media tanam lainnya. Kejenuhan basa (KB) pada media tanam tidak berbeda nyata pada berbagai perlakuan (Tabel 4). Hal ini sejalan dengan hasil penelitian Hemwong dan Cadisch (2011) yang menunjukkan penambahan arang (bambu, sekam dan eukaliptus) pada lahan padi dapat meningkatkan KTK, total $\mathrm{C}$ dan $\mathrm{N}$ dan kandungan $\mathrm{K}, \mathrm{Ca}$ dan $\mathrm{Mg}$ dapat dipertukarkan.

Komposisi media tanam berpengaruh nyata terhadap sifat fisik media tanam. Kadar air media tanam tanah tidak berbeda nyata dengan arang sekam : tanah, tetapi nyata lebih besar dibandingkan dengan komposisi media tanam lain, terutama dengan arang sekam : cocopeat (Tabel 5). Dengan demikian, komposisi media arang sekam : tanah memiliki kemampuan menahan air yang setara dengan tanah. Bobot isi dan bobot jenis media tanam arang sekam : cocopeat paling rendah dibandingkan dengan komposisi media tanam lain (Tabel 5). Bobot isi menunjukkan kepadatan media tanam, karena merupakan perbandingan antara bobot kering dan volume media tanam, termasuk pori-pori media tanam. Sementara, bobot jenis merupakan perbandingan antara bobot dan volume bagian padat media tanam.

Bobot isi dan bobot jenis media tanam arang sekam : cocopeat yang rendah disebabkan karena campuran media tanam ini berupa bahan organik. Bobot bahan organik lebih ringan dibandingkan dengan komponen tanah lain pada volume yang sama (Hardjowigeno, 2007). Kondisi ini membuat kombinasi arang sekam : cocopeat kurang baik dijadikan media tanam tabulampot, karena kemampuan menahan air, bobot isi dan bobot jenis yang terlalu rendah. Selain itu, bobotnya yang terlalu ringan, membuat pot dengan komposisi arang sekam : cocopeat mudah rebah bila tertiup angin kencang. Penggunaan cocopeat perlu dikombinasikan dengan bahan lain. Bhardwaj (2014), melaporkan penambahan cocopeat pada media campuran vermikompos + pasir + tanah kolam memberikan hasil yang baik bagi peubah perkecambahan dan pertumbuhan vegetatif bibit pepaya.

Tabel 4. Kapasitas tukar kation, basa-basa dapat ditukar dan kejenuhan basa media tanam pada 16 MST (NH4-Acetat 1N, pH7)

\begin{tabular}{lcccccrr}
\hline \multicolumn{1}{c}{ Komposisi Media } & KTK & $\mathrm{Ca}$ & $\begin{array}{c}\mathrm{Mg} \\
\left(\mathrm{cmol}_{\mathrm{c}} \mathrm{kg}^{-1}\right)\end{array}$ & Na & Jumlah & $\begin{array}{r}\text { KB } \\
(\%)\end{array}$ \\
\hline A:T $(1: 1)$ & $9.55^{\mathrm{ab}}$ & $5.74^{\mathrm{ab}}$ & $1.54^{\mathrm{a}}$ & $0.40^{\mathrm{a}}$ & $0.40^{\mathrm{a}}$ & $9.24^{\mathrm{a}}$ & 95.50 \\
C:T (1:1) & $16.39^{\mathrm{b}}$ & $10.87^{\mathrm{bc}}$ & $3.99^{\mathrm{d}}$ & $2.33^{\mathrm{b}}$ & $0.58^{\mathrm{ab}}$ & $16.58^{\mathrm{b}}$ & 98.00 \\
A:C $(1: 1)$ & $22.28^{\mathrm{c}}$ & $15.16^{\mathrm{c}}$ & $2.79^{\mathrm{c}}$ & $3.93^{\mathrm{c}}$ & $1.58^{\mathrm{c}}$ & $24.67^{\mathrm{c}}$ & 100.00 \\
A:C:T $(1: 1: 1)$ & $16.92^{\mathrm{bc}}$ & $8.20^{\mathrm{ab}}$ & $2.34^{\mathrm{b}}$ & $1.61^{\mathrm{ab}}$ & $0.75^{\mathrm{b}}$ & $12.91^{\mathrm{ab}}$ & 80.50 \\
T & $7.75^{\mathrm{a}}$ & $4.93^{\mathrm{a}}$ & $1.24^{\mathrm{a}}$ & $1.17^{\mathrm{a}}$ & $0.52^{\mathrm{ab}}$ & $7.87^{\mathrm{a}}$ & 76.00 \\
\hline
\end{tabular}

Keterangan: Nilai rata-rata pada kolom yang sama diikuti huruf yang sama tidak berbeda nyata menurut uji selang berganda Duncan taraf 5\%. A: arang sekam, T: tanah, C: cocopeat

Tabel 5. Sifat fisik media tanam pamelo pada umur 24 MST

\begin{tabular}{lccc}
\hline \multirow{2}{*}{ Komposisi Media } & \multicolumn{3}{c}{ Sifat Fisik Media Tanam } \\
\cline { 2 - 4 } & Kadar Air $(\%)$ & Bobot Isi $(\mathrm{g} / \mathrm{cc})$ & Bobot Jenis $(\mathrm{g} / \mathrm{cc})$ \\
\hline A:T $(1: 1)$ & $30.20^{\mathrm{bc}}$ & $0.63^{\mathrm{d}}$ & $1.72^{\mathrm{b}}$ \\
C:T $(1: 1)$ & $29.40^{\mathrm{b}}$ & $0.49^{\mathrm{c}}$ & $2.18^{\mathrm{b}}$ \\
A:C $(1: 1)$ & $20.35^{\mathrm{a}}$ & $0.15^{\mathrm{a}}$ & $0.55^{\mathrm{a}}$ \\
A:C:T $(1: 1: 1)$ & $24.70^{\mathrm{ab}}$ & $0.40^{\mathrm{b}}$ & $2.18^{\mathrm{b}}$ \\
T & $35.70^{\mathrm{c}}$ & $0.94^{\mathrm{e}}$ & $2.36^{\mathrm{b}}$ \\
\hline
\end{tabular}

Keterangan: Nilai rata-rata pada kolom yang sama diikuti huruf yang sama tidak berbeda nyata menurut uji selang berganda Duncan taraf 5\%. A: arang sekam, T: tanah, C: cocopeat 
Berdasarkan respon tanaman terhadap komposisi media tanam, dan kondisi kimia dan fisik media tanam, kombinasi arang sekam : tanah menunjukkan hasil yang lebih baik dibandingkan dengan komposisi media tanam lainnya. Hal yang sama dilaporkan oleh Irawan dan Kafiar (2015) pada bibit cempaka wasian, Hidayah dan Irawan (2015) pada setek jabon merah, dan Agustin et al. (2014) pada bibit cempaka kuning. Selain itu, setek pohpohan (Pilea trinervia Wight.) yang ditanam pada media arang sekam+kompos memiliki persentase hidup, persentase berakar, dan jumlah daun lebih tinggi dari media lain (Muslimawati et al., 2015). Pengaruh arang sekam yang demikian, disebabkan kemampuannya menjerap senyawa organik seperti pupuk dan pestisida, meningkatkan aktivitas mikroba, menahan kelembaban dan hara $\mathrm{N}$ selama pengomposan dan memperlambat pelepasan hara pada pupuk (Theeba et al., 2012). Sekam padi juga banyak mengandung silikat. Abu sekam padi terdiri atas $80.26 \% \mathrm{Si}, 0.38 \% \mathrm{P}, 1.28 \% \mathrm{~K}, 0.211 \%$ $\mathrm{Mg}$ dan 0.56\% Ca (Hashim et al., 1996). Silikat dapat mengurangi toksisitas $\mathrm{Al}$, meningkatkan ketersediaan fosfat dengan cara melepaskan ikatan fosfat dari $\mathrm{Ca}, \mathrm{Mg}, \mathrm{Al}$ dan $\mathrm{Fe}$, meningkatkan konsentrasi enzim rubisco dan meningkatkan ketahanan terhadap cekaman biotik dan abiotik (Snyder et al., 2007).

Respon tanaman pamelo terhadap komposisi media cocopeat : tanah tidak sebaik arang sekam tanah, diduga hal ini disebabkan oleh nisbah $\mathrm{C} / \mathrm{N}$ yang tinggi pada komposisi media tersebut. Disamping itu, walaupun telah melalui proses pencucian, kemungkinan cocopeat masih mengandung tanin, yang merupakan penghalang mekanik dalam penyerapan hara (Sukarman et al., 2012).

\section{KESIMPULAN}

Hasil penelitian menunjukkan komposisi media tanam yang paling sesuai untuk pertumbuhan (tinggi tanaman dan volume akar) tanaman pamelo adalah tanah : arang sekam, sedangkan yang kurang sesuai adalah arang sekam : cocopeat. Media tanam arang sekam : cocopeat memiliki kandungan $\mathrm{N}$, C, nisbah $\mathrm{C} / \mathrm{N}$, bahan organik, $\mathrm{K}_{2} \mathrm{O}$ dan nilai tukar kation lebih tinggi, tetapi kadar air, bobot isi dan bobot jenis paling rendah dari media tanam lain.

Pertumbuhan tanaman (tinggi, jumlah daun dan volume akar) tanaman pamelo pada volume media tanam $30 \mathrm{~L}$ lebih besar dibandingkan dengan pada volume media tanam $10 \mathrm{~L}$, tetapi tidak berbeda nyata dengan pada pot 20 L, kecuali jumlah daun. Dengan demikian, volume media tanam $20 \mathrm{~L}$ masih sesuai untuk pertumbuhan tanaman pamelo hingga 24 MST.

\section{DAFTAR PUSTAKA}

Abera, G., E. Wolde-meskel, L.R. Bakken. 2012. Carbon and nitrogen mineralization dynamics in different soils of the tropics amended with legume residues and contrasting soil moisture contents. Biol. Fertil. Soils. 48: 51-66.

Agustin, A.D., M. Riniarti, Duryat. 2014. Pemanfaatan limbah serbuk gergaji dan arang sekam padi sebagai media sapih untuk cempaka kuning (Michelia champaca). J. Sylva Lestari. 2: 49-58.

Bhardwaj, R.L. 2014. Effect of growing media on seed germination and seedling growth of papaya cv. 'Red lady'. African J. Plant Sci. 8: 178-184.

Hardjowigeno, S. 2007. Ilmu Tanah. Akademika Presindo.

Hashim, A.B., Aminuddin, H., Siva, K.B. 1996. Nutrient content of rice husk of some Malaysian rice varities. Pertanika J. Trop. Agric. Sci. 19: 77-80 .

Hemwong, S., G. Cadisch. 2011. Charcoal amendments to improve soil fertility and rice production in Northeast Thailand. Food Security Center Brief No. 3: 1-4.

Hidayah, H.N., A. Irawan. 2015. Kesesuaian media sapih terhadap persentase hidup semai jabon merah (Anthocephalus macrophyllus (Roxb.) Havil). Pros. Sem. Nas. Masy. Biodiv Indon. 1: 6974. 
Ikeura, H., T. Tokuda, Y. Hayata. 2012. Required amounts of medium and fertilizer for potted culture of zucchini. Agric. Sci. 3: 816-821.

Irawan, A., Y. Kafiar. 2015. Pemanfaatan cocopeat dan arang sekam padi sebagai media tanam bibit cempaka wasian (Elmerrilia ovalis). Prosiding Seminar Nasional Masyarakat Biodiversitas Indonesia 1: 805-808.

Khan, M.M., M.A. Khan, M. Abbas, M.J. Jaskani, M.A. Ali, H. Abbas. 2006. Evaluation of potting media for the production of rough lemon nursery stock. Pak. J. Bot. 38: 623-629.

Kusmarwiyah, R., S. Erni. 2011. Pengaruh media tumbuh dan pupuk organik cair terhadap pertumbuhan dan hasil tanaman seledri (Apium graveolens $\mathrm{L}$.). Crop Agro. 4: 7-12.

Mataa, M., S. Tominaga. 1998. Effects of root restriction on tree development in Ponkan mandarin (Citrus reticulata Blanco). J. Amer. Soc. Hort. Sci. 123: 651-655.

Muryati, L. Octriana, D.E. Ida, P.J. Santoso, D. Sunarwati. 2009. Effect of organic fertilizers on susceptibility of potted durian seedlings to Phytophthora diseases. J. Fruits Ornament Plant Res. 17: 67-77.

Muslimawati, N., K. Suketi, A.D. Susila. 2015. Pertumbuhan stek batang pohpohan (Pilea trinervia Wight.) pada umur tanaman, bagian batang, dan media tanam yang berbeda. J. Hort. Indonesia. 6: 91-98.

Nurhidayati, Mariati. 2014. Utilization of maize cob biochar and rice husk charcoal as soil amendments for improving acid soil fertility and productivity. J. Degraded Mining Lands Management. 2: 223-230.

Ray, J.D., T.R. Sinclair. 1998. The effect of pot size on growth and transpiration of maize and soybean during water deficit stress. J. Exp. Bot. 49: 1381-1386.

Shanmugasundaram, R., T. Jeyalakshmi, S.S. Mohan, M. Saravanan, A. Goparaju, P.B. Murthy. 2014. Coco peat - an alternative artificial soil ingredient for the earthworm toxicity testing. J. Toxicology Environ. Health Sci. 6: 512.

Snyder, G.H., V.V. Matichenkov, L.E. Datnoff. 2007. Silicon. In Barker A.V., Pilbeam, D.J. (Eds.). Handbook of Plant Nutrition. CRC Taylor and Francis Group. P. 551-568.

Soemeinaboedhy, I.N., R.S. Tejowulan. 2007. Pemanfaatan berbagai macam arang sebagai sumber unsur hara $\mathrm{P}$ dan $\mathrm{K}$ serta sebagai pembenah tanah. Agroteksos. 17: 114-122.

Sukarman, R. Kainde, J. Rombang, A. Thomas. 2012. Pertumbuhan bibit sengon (Paraserianthes falcataria) pada berbagai media tumbuh. Eugenia. 18: 215-220.

Surata, I.K. 2012. Pertumbuhan semai cendana (Santalum album Linn.) pada beberapa ukuran kantung plastik di daerah semiarid. J. Penel. Kehutanan Wallacea 1: 13-25.

Thamrin, M., S. Susanto, A.D. Susila, A. Sutandi. 2013. Hubungan konsentrasi hara nitrogen, fosfor, dan kalium daun dengan produksi buah sebelumnya pada tanaman jeruk pamelo. J. Hort. 23: 225234.

Theeba, M., R.T. Bachmann, Z.I. Illani, M. Zulkefli, M.H.A. Husni, A.W. Samsuri. 2012. Characterization of local mill rice husk charcoal and its effect on compost properties. Malaysian J. Soil Sci. 16: 89-102.

Tsai, H.L, S.K.C. Chang, S.J. Chang. 2007. Antioxidant content and free radical scavenging ability of fresh red pummelo (Citrus grandis (L.) Osbeck) juice and 
freeze-dried products. J. Agric. Food Chem. 55: 2867-2872.

Van Iersel, M. 1997. Root restriction effects on growth and development of salvia (Salvia splendens). Hort. Sci. 32: 11861190.

Whipker, B.E, S. Dasoju. 1998. Growth and flowering responses to foliar applications of daminozide, paclobutrazol dan uniconazole. Hort.Tech. 8: 86-88.

Wijanarko, A., B.H. Purwanto, D. Shiddieq, D. Indradewa. 2012. Pengaruh kualitas bahan organik dan kesuburan tanah terhadap mineralisasi nitrogen dan serapan $\mathrm{N}$ oleh tanaman ubikayu di ultisol. J. Perkebunan Lahan Tropika 2: $1-14$.

Yang, Z., G. Hammer, E. van Oosterom, D. Rochais, K. Deifel. 2010. Effects of pot size on growth of maize and sorghum plants. Proc. $1^{\text {st }}$ Australian Summer Grains Conference, Gold Coast, Australia, $21^{\text {st }}-24^{\text {th }}$ June 2010.

Zulkarnain, M., B. Prasetya, Soemarno. 2013. Pengaruh kompos, pupuk kandang, dan custom-bio terhadap sifat tanah, pertumbuhan dan hasil tebu (Saccharum officinarum 1.) pada entisol di Kebun Ngrangkah - Pawon, Kediri) Indonesia. Green Tech. J. 2(1): 44-52. 